\title{
Study on Maternal and Immediate Fetal Outcome of Placenta Previa
}

\section{Lama $\mathbf{S}^{1}$, Ranjit $\mathbf{S}^{2}$}

${ }^{1}$ Department of Obstetrics and Gynaecology, Patan Academy of Health Sciences, Lalitpur, Nepal, ${ }^{2}$ Department of Neuroscience and Neurosurgery, The Mount Sainai Hospital, New York, NY, USA

Received: 9-Apr-2016; Accepted: 10 Dec-2016

Aims: This study aimed to analyze the demographic profile, maternal and fetal outcome of placenta previa.

Methods: This was a retrospective study done at Patan Academy of Health Sciences. The study population comprised of all the patients that had Caesarean section for placenta previa from April 2012 to October 2015. All patients diagnosed with placenta previa clinically using ultrasonograph or incidentally during Caesarean sections were recruited in this study. The data was obtained from medical records and hospital database system. Individual charts were reviewed and data on various parameters was collected.

Results: In Patan Hospital, there was a total of 126 placenta previa cases out of 21,552 deliveries during the two and half year period and hence, the incidence was $0.58 \%$. We were able to retrieve patient records of only 108 of 126 cases. The incidence of placenta previa was higher with increasing maternal age $\geq 30$ years, there were $45(41.67 \%)$ cases, it was more common in multigravida, $71(65.74 \%)$. We found that associated risk factors included previous Caesarean section, multiparity and dilatation and curettage, there were $44(40.74 \%)$. Eleven patients required blood transfusion, seven of them had blood loss of $1000-1400 \mathrm{ml}$, one had blood loss of $2000 \mathrm{ml}$. Also, Caesarean hysterectomy were performed in two patients. In terms of fetal outcomes, $40(37.04 \%)$ were preterm birth and $32(29.63 \%)$ of the babies had low birth weight. There was one incident of congenital anomaly, one intrauterine fetal death and six neonatal deaths.

Conclusions: Placenta previa is an obstetric complication that is potentially life-threatening to both the mother and the baby.

Keywords: blood loss; Caesarean section; placenta previa.

\section{INTRODUCTION}

Obstetric hemorrhage is one of the most common causes of maternal morbidity and mortality worldwide. Placenta previa is a high risk pregnancy which complicates $0.4-0.6 \%$ of all deliveries. ${ }^{1}$ Placenta previa is defined as implantation of placenta in lower uterine segment, overlying or approaching the internal cervical os. ${ }^{2}$ It is classified as Type I (low lying), Type II (marginal), Type III (partial central or incomplete), Type IV (total or central). ${ }^{3}$ Risk factors of placenta previa includes high parity, advancing maternal age, previous Cesaerean section (CS), multiple pregnancy, previous history of placenta previa, dilatation and curettage (D and C) and uterine surgery like myomectomy. Major complication of placenta previa are haemorrhagic shock, postpartum haemorrhage (PPH), anaemia,

\section{CORRESPONDENCE}

Dr. Sushma Lama,

Department of Obstetrics and Gynaecology,

Patan Academy of Health Sciences, Nepal.

Email: drsushmalama@gmail.com,

Phone: +977 -9849497223. caesarean hysterectomy, low birth weight, maternal and perinatal death. ${ }^{4}$ Early diagnosis of placenta previa and a timely intervention with arrangement of blood, good anaesthetic, surgical and paediatric team can improve maternal and perinatal outcome. The objective of this study is to determine the incidence, risk factors and maternal-fetal outcomes in woman with placenta previa in our clinical setting.

\section{METHODS}

This was a retrospective study. The study population comprised of all the patients that had Caesarean section for placenta previa at Patan Hospital from April 2012 to October 2015. All patients diagnosed with placenta previa clinically, ultrasonographically or incidental discovery during Caesarean section were recruited in this study. Following approval from the research committee, the study was commenced. The data was obtained from medical records and hospital database system.

\section{Individual chart were reviewed and data were collected on following parameters:}

On maternal- age, parity, gestational age, type of placenta previa, previous CS, myomectomy, D and 
C, manual removal of placenta, uterine anomaly, malpresentation, multiple pregnancy, type of surgery elective vs emergency, duration of hospital stay, complications such as post partum haemorrhage (amount of blood loss), blood transfusion, caesarean hysterectomy, placenta accreta, abruptio placenta, maternal mortality, renal failure, wound infection and puerperal pyrexia.

On fetal - birth weight, preterm, still birth, intrauterine fetal death and neonatal death.

Data entry was entered in a master chart and descriptive analysis was performed.

\section{RESULTS}

During this study period the total number of deliveries were 21,552 and the incidence of placenta previa was $0.58 \%$. The total number of placenta previa were 126 however, we were able to retrieve patient records of 108 cases only.

108 patients were enrolled for the study, their demographic information at enrollment is shown in Table 1. 40 patients were between the ages of 2629 years $(37.04 \%)$. The minimum age was 19 years and maximum was 39 years. $37(34.26 \%)$ patients were primigravida while 71 patients $(65.74 \%)$ were multigravida, upto gravida nine. Total of $4(3.70 \%)$ patients belonged to the gestational age of $<28$ weeks, $11(10.19 \%)$ were between 28 and 33 weeks, $25(23.15 \%)$ were between 34 and 36 weeks and majority of the patients $68(62.96 \%)$ belonged to $\geq 37$ weeks of gestation.

Table 1. Distribution of age, parity and gestational age.

\begin{tabular}{|lll|}
\hline Characteristics & Categories & Frequency \\
\hline & $<20$ & $4(3.70 \%)$ \\
& $20-25$ & $19(17.59 \%)$ \\
Age gr in years & $26-29$ & $40(37.04 \%)$ \\
& $30-35$ & $33(30.56 \%)$ \\
& $>35$ & $12(11.11 \%)$ \\
Parity & Primi & $37(34.26 \%)$ \\
Gestational age & Multi & $71(65.74 \%)$ \\
& $<28$ & $4(3.70 \%)$ \\
& $28-33$ & $11(10.19 \%)$ \\
& $34-36$ & $25(23.15 \%)$ \\
& $\geq 37$ & $68(62.96 \%)$ \\
\hline
\end{tabular}

Type I placenta previa was seen in 1 patient $(0.93$ $\%$ ) which was the least common among all placenta previa. $38(35.19 \%)$ patients were Type IIA, majority of the patients were Type IIB which was 40 (37.04 $\%$, Type III was seen in $3(2.78 \%)$ patients, and Type
IV $26(24.07 \%)$. Among the patients with placenta previa $71(65.74 \%)$ of patients had emergency Caesarean section while 37 (34.26\%) of the patients had elective Caeserean section. (Table 2)

Table 3 shows the risks factors associated with placenta previa. Total of $8(7.41 \%)$ of the patient had previous one CS, $12(11.11 \%)$ of patients had one D and C, $1(0.93 \%)$ had two D and $\mathrm{C}$ and 11 $(10.19 \%)$ were multiparous. $5(4.63 \%)$ patients were multiparous with one $\mathrm{D}$ and $\mathrm{C}$ while $2(1.85 \%)$ patients were multiparous with three $\mathrm{D}$ and $\mathrm{C}, 1$ $(0.93 \%)$ of the patients had one previous CS with one D and C, $2(1.85 \%)$ of the patients were multiparous and had a previous CS with one D and C. $1(0.93 \%)$ patient was multiparous and had a previous CS with two D and C. $1(0.93 \%)$ patient was multiparous and had a previous CS with three $\mathrm{D}$ and $\mathrm{C}$.

Table 2. Distribution of type of placenta previa and type of surgery.

\begin{tabular}{|lll|}
\hline Characteristics & Categories & Frequency \\
\hline $\begin{array}{l}\text { Type of placenta } \\
\text { previa }\end{array}$ & I & $1(0.93 \%)$ \\
& IIA & $38(35.19 \%)$ \\
& IIB & $40(37.04 \%)$ \\
& III & $3(2.78 \%)$ \\
\hline \multirow{2}{*}{ Type of surgery } & IV & $26(24.07 \%)$ \\
& Emergency & $71(65.74 \%)$ \\
& Elective & $37(34.26 \%)$ \\
\hline
\end{tabular}

Table 3. Distribution of risks factors with cases.

\begin{tabular}{|lll|}
\hline Characteristics & Categories & Frequency \\
\hline Risks factors & $\begin{array}{l}\text { Previous caesarean } \\
\text { section }\end{array}$ & $8(7.41 \%)$ \\
& $\begin{array}{l}\text { 1 Dilatation and } \\
\text { Curettage }\end{array}$ & $12(11.11 \%)$ \\
& $\begin{array}{l}\text { 2 Dilatation and } \\
\text { Curettage }\end{array}$ & $1(0.93 \%)$ \\
& Multiparity & $11(10.19 \%)$ \\
& $\begin{array}{l}\text { Multiparity + 1 D and C } \\
\text { Multiparity + 3 D and C }\end{array}$ & $2(1.65 \%)$ \\
& $\begin{array}{l}\text { Previous CS + 1 D } \\
\text { and C }\end{array}$ & $1(0.93 \%)$ \\
& $\begin{array}{l}\text { Previous CS + } \\
\text { multiparity + D and C }\end{array}$ & $2(1.85 \%)$ \\
& $\begin{array}{l}\text { Previous CS + } \\
\text { multiparity + 2 D and C }\end{array}$ & $1(0.93 \%)$ \\
& $\begin{array}{l}\text { Previous CS + } \\
\text { multiparity + 3 D and C }\end{array}$ & $1(0.93 \%)$ \\
\hline
\end{tabular}

Table 4 shows the maternal complications. There were blood losses of $500-900 \mathrm{ml}$ in $10(9.26 \%)$ patients. 7 
$(6.48 \%)$ of the patients had blood loss of about 1000 $1400 \mathrm{ml}$ while one $(0.93 \%)$ patient had blood loss of about $2000 \mathrm{ml}$. Eleven of the patients required blood transfusion, maximum amount of blood transfused was five pints of fresh blood and two pints of fresh frozen plasma in one patient who lost approximately $2000 \mathrm{ml}$ of blood. Abruptio placenta was seen in 8 $(7.41 \%)$ of the cases and placenta accreta in $3(2.78 \%)$ of the cases of placenta previa. Uterine packing was done in $2(1.85 \%)$ cases for placental bed bleeding. Two of the patients (1.85\%) underwent caesarean hysterectomy, both of those patients had Type IV placenta previa with previous CS and were also associated with placenta accreta. Wound infection was seen in $3(2.78 \%)$ and puerperal pyrexia was seen in $3(2.78 \%)$ of the cases . Malpresentation was seen in $16(14.81 \%)$ cases, which included $9(8.33 \%)$ breech , $1(0.93 \%)$ oblique and $6(5.56 \%)$ transverse lie.

Table 4. Distribution of maternal complications.

\begin{tabular}{|llc|}
\hline Characteristics & Categories & Frequency \\
\hline Blood loss & $500 \mathrm{ml}$ to $900 \mathrm{ml}$ & $10(9.26 \%)$ \\
& $1000 \mathrm{ml}$ to $1400 \mathrm{ml}$ & $7(6.48 \%)$ \\
\hline Blood Transfusion & $1500 \mathrm{ml}$ to $2000 \mathrm{ml}$ & $1(0.93 \%)$ \\
\hline Abruptio Placenta & & $11(10.19 \%)$ \\
Placenta Accreta & & $8(7.41 \%)$ \\
\hline Uterine Packing & & $3(2.78 \%)$ \\
Caesarean & & $2(1.85 \%)$ \\
Hysterectomy & & $2(1.85 \%)$ \\
Wound Infection & & $3(2.78 \%)$ \\
Puerperal Pyrexia & & $3(2.78 \%)$ \\
\hline Fetal & & \\
Malpresentation & & $9(8.33 \%)$ \\
\hline & Breech & $1(0.93 \%)$ \\
\hline & Oblique & $6(5.56 \%)$ \\
\hline
\end{tabular}

Table 5 shows the duration of hospitalization. Majority of the patients, $77(71.30 \%)$ were discharged on day three of hospitalization. $20(18.52 \%)$ were discharged on day 5-10. Three patients (2.78\%) remained hospitalized for ten days due to puerperal pyrexia, wound infection and one had undergone caesarean hysterectomy. $8(7.41 \%)$ of the patients had to remain hospitalized longer not due to their own clinical condition, but to accompany their babies in either nursery or NICU/PICU, maximum duration of upto 43 days.
Table 5. Distribution of hospitalization.

\begin{tabular}{|lll|}
\hline Characteristics & Categories & Frequency \\
\hline Blood loss & $3-4$ & $77(71.30 \%)$ \\
& $5-10$ & $20(18.52 \%)$ \\
& $>10$ & $3(2.78 \%)$ \\
Waiting for baby & $>16$ & $8(7.41 \%)$ \\
\hline
\end{tabular}

Table 6 shows the fetal outcome in which neonatal weight of $<1.5 \mathrm{~kg}$ was seen in $8(7.41 \%)$ cases, $1.5-2.4 \mathrm{~kg}$ was seen in $24(22.22 \%), 2.5-3.5 \mathrm{~kg}$ in 72 ( $66.67 \%$ ) and $>3.5 \mathrm{~kg}$ was seen in $4(3.70 \%)$ of the cases. Preterm birth was seen in $40(37.04 \%)$ of the cases. There was one $(0.93 \%)$ IUFD. There were 6 $(5.56 \%)$ NND. One baby $(0.93 \%)$ had congenital anomaly with no cranial vault, had low set ear, ascites and the baby died immediately after birth.

Table 6. Distribution of fetal outcome.

\begin{tabular}{|lll|}
\hline Characteristics & Categories & Frequency \\
\hline $\begin{array}{l}\text { Birth weight } \\
(\mathrm{kgs})\end{array}$ & $<1.5$ & $8(7.41 \%)$ \\
& $1.5-2.4$ & $24(22.22 \%)$ \\
& $2.5-3.5$ & $72(66.67 \%)$ \\
& $>3.5$ & $4(3.70 \%)$ \\
& Preterm birth & $40(37.04 \%)$ \\
& Intrauterine fetal death & $1(0.93 \%)$ \\
& Early neonatal death & $6(5.56 \%)$ \\
& Congenital anomaly & $1(0.93 \%)$ \\
\hline
\end{tabular}

\section{DISCUSSION}

The incidence of placenta previa was higher with increasing maternal age $\geq 30$ years, in which there were $45(41.67 \%)$ cases, it was more common in multigravida, $71(65.74 \%)$. The associated risk factors included previous Caesarean section, multiparity and dilatation and curettage, there were $44(40.74 \%)$ cases. There were 40 (37.04\%) preterm birth and $32(29.63 \%)$ of the babies had low birth weight. The incidence of placenta previa in our study was $0.58 \%$ a total of 126 placenta previa cases out of 21,552 deliveries. There are similar other studies which shows different incidence. A study done in Jos University Teaching Hospital, by A.S. Anzaku et $\mathrm{a}^{5}$ over a three and half-year periods where there were 10,895 deliveries and 135 cases of placenta previa, thus an incidence of $1.24 \%$. A retrospective study was done at Tribhuwan University Teaching Hospital, kathmandu by Neebha Ojha ${ }^{7}$, over a four years duration showed 82 cases of cesarean sections 
done for placenta previa, which is for $0.55 \%$ of the total deliveries which was similar to our study.

In our study, the risks factors included were multiparity, previous CS and D and C. Total of 8 (7.41\%) of the patient had previous one CS and 12 (11.11\%) of patients had one D and C. Also, $1(0.93 \%)$ had two D and C and 11 (10.19\%) were multiparous. While $5(4.63 \%)$ patients were multiparous with one $\mathrm{D}$ and $\mathrm{C}, 2(1.85 \%)$ patients were multiparous with three D and C, $1(0.93 \%)$ of the patients had one previous CS with one D and C, $2(1.85 \%)$ of the patients were multiparous and had a previous $\mathrm{CS}$ with one $\mathrm{D}$ and $\mathrm{C}, 1(0.93 \%)$ patients were multiparous and had a previous CS with two D and C . 1 ( 0.93\%) patient was multiparous and had a previous CS with three $\mathrm{D}$ and $\mathrm{C}$ whereas a Study done at Civil Hospital, Ahmadabad by Anand D et al ${ }^{8}$ showed the associated risks factors were multigravida $66(75 \%)$, previous CS $15(17 \%)$, previous Curettage $7(8 \%)$, past history of placenta Previa 8 (9\%) and multiple gestations $7(8 \%)$. Similarly a study done in Jos University Teaching Hospital, by A.S. Anzaku ${ }^{5}$ identified the risk factors were previous CS $(40.7 \%)$, grandmultiparity $(28.3 \%)$, D and C (20.4\%), multiple pregnancies $(6.2 \%)$ and previous history of placenta praevia $(4.2 \%)$.

Our study showed complications like PPH in 8 (7.41\%), abruption placenta $8(10.19 \%)$, placenta accreta $3(2.78 \%)$, caesarean hysterectomy 2 (1.85\%), fetal malpresentation 16 (14.81\%) whereas a retrospective cohort study done in Nova Scotia, Canada identified maternal complication like postpartum bleeding (RR-1.86), hysterectomy (RR33.26), blood transfusion (RR-10.05), septicemia (RR5.55). Risk factor for hysterectomy in women with placenta previa included presence of placenta accreta and previous CS. ${ }^{6}$ Whereas in our study patients who underwent caesarean hysterectomy, both had Type IV placenta previa, previous Caesarean section and were also associated with placenta accreta. Another study

\section{REFERENCES}

1. Faiz AS, Ananth CV. Etiology and risk factors for placenta previa: An overview and meta-analysis of observational studies. J Matern Fetal Neonatal Med. 2003; 13:175-90.

2. Elsayes KM, Trout AT, Friedkin AM, Liu PS, Bude RO, Platt JF et al. Imaging of the placenta: a multimodality pictorial review. Radiographics. 2009; 29(5): 1371- 91.

3. Neilson JP. Antepartum haemorrhage: Edmonds DK editor; Dewhursts text book of Obstet and Gynecol for post graduates. 6th edition. Blackwell Scientific London, Oxford. 1995:164-74.

4. Sinha P, Kuruba N, Anteparum haemorrhage: an update. J Obstet Gynecol. 2008;28: 377-81. by A.S. Anzaku et $\mathrm{al}^{5}$ showed complications like postpartum anaemia (6.7\%), caesarean hysterectomy $(3.0 \%)$, wound infection $(2.2 \%)$ and there were two maternal deaths $(1.48 \%)$. In our study there was no maternal mortality.

Our study showed $40(37.04 \%)$ preterm birth and 32 ( $29.63 \%)$ of the babies were low birth weight. There was one IUFD $(0.93 \%)$, six NND $(5.56 \%)$ and one baby with congenital anomaly $(0.93 \%)$. However Study at Civil Hospital, Ahmadabad by Anand D et $\mathrm{al}^{8}$ showed $68(74.7 \%)$ were preterm babies and 65 (71.4\%) were low birth weight babies, 4 (4.2\%) were still born while there were $18(20 \%)$ early neonatal deaths observed due to prematurity and low birth weight.

There are some limitations of this study. All the cases recruited in this study was from Patan Hospital alone so the data represents a narrow population. A multicenter based larger population study might have a different outcome compared to that of this study. There is no randomization and case control in this study. The duration of this study was also short and some files were also missing. Based on this study we can design a bigger study with power calculation and narrow down the independent variables in order to perform a logistic regressional analysis to determine the association between the dependent and independent variables.

\section{CONCLUSIONS}

Our study showed incidence of placenta previa increases with maternal age $\geq 30$ yrs and it is more common in multigravida. In addition Type IIB placenta previa was more common. In conclusion placenta previa is a serious and life threatening complication for both a mother and a fetus, the outcome of this condition could be improved by early registration, regular ANC, early detection of high risks cases and early referral to higher care center with facilities for CS and prompt availability of blood.

5. A.S Anzaku, J Musa, Placenta Praevia: Incidence, Risk Factors, Maternal And Fetal Outcomes In A Nigerian Teaching Hospital. Jos Journal of Medicine. 2010;42-6.

6. Crane JM, Van den Hof MC, Dodds L, Armson BA, Liston R Maternal complications with placenta previa. Am J Perinatol. 2000;17(2):101-5.

7. Ojha N. Obstetric factors and pregnancy outcome in placenta previa. Journal of Institute of Medicine. 2012; 34(2):38-41.

8. Bhatt AD, Meena A, Desai MR. Maternal and Perinatal Outcome in Cases of Placenta Previa. International Journal of Science and Research. 2014;299- 301.

9. Farhat N. Incidence, causes and outcome of placenta previa, Journal of postgraduate medical institute. 1996;17(1):104. 